University for Business and Technology in Kosovo

UBT Knowledge Center

UBT International Conference

2017 UBT International Conference

Oct 27th, 3:00 PM - 4:30 PM

\title{
Mobile Cloud Computing: A new way of Cloud Computing
}

\author{
Festim Halili \\ University of Tetova, festim.halili@unite.edu.mk \\ Verda Misimi \\ University of Tetova, verda.misimi@unite.edu.mk \\ Rilinda Iseini \\ University of Tetova, rilinda_iseini@hotmail.com \\ Mirije Salihi \\ University of Tetova, mirije_salihi@hotmail.com
}

Follow this and additional works at: https://knowledgecenter.ubt-uni.net/conference

Part of the Computer Engineering Commons, and the Computer Sciences Commons

\section{Recommended Citation \\ Halili, Festim; Misimi, Verda; Iseini, Rilinda; and Salihi, Mirije, "Mobile Cloud Computing: A new way of Cloud Computing" (2017). UBT International Conference. 85. \\ https://knowledgecenter.ubt-uni.net/conference/2017/all-events/85}

This Event is brought to you for free and open access by the Publication and Journals at UBT Knowledge Center. It has been accepted for inclusion in UBT International Conference by an authorized administrator of UBT Knowledge Center. For more information, please contact knowledge.center@ubt-uni.net. 


\title{
Mobile Cloud Computing: A new way of Cloud Computing
}

\author{
Festim Halili ${ }^{1}$, Verda Misimi ${ }^{1}$, Rilinda Iseini ${ }^{1}$, Mirije Salihi $^{1}$ \\ ${ }^{1}$ University of Tetova, Faculty of Math and Natural Sciences, Department of \\ Informatics, Tetovo, Macedonia \\ \{festim.halili, verda.misimi\}@unite.edu.mk, \{rilinda_iseini, mirije_salihi \\ \}@hotmail.com
}

\begin{abstract}
Cloud Computing seems to be the most promising technology of the century we are living. It provides a new manner of sharing distributed resources and services that may be part of different organizations, geographically located in different places and different time zones. Mobile Cloud Computing offers partially the same functionality, with the only additional requirement that, at least, some of the devices are mobile. In this paper, we will try to provide a detailed explanation of Mobile Cloud Computing concept by providing different examples, figures and charts showing usage, accessibility, pros and cons and comparison of different cloud platforms.
\end{abstract}

Keywords: Cloud Computing, Mobile Cloud Computing, Smartphones, IaaS

\section{Introduction}

A couple of decades ago, cell phones were just some devices that simply allowed users to perform phone calls while not at a post office or home. But all this changed thanks to the massive investments in internet connectivity, which made possible the easy access, and thus, allowing a huge demand on mobile phones, that today are used twice or even more than a desktop computer was about one decade ago. [1]

Cloud computing appears as the latest evolution in delivering computing power, allowing even small or micro organizations to have access to a higher level of processing power, or totally "virtaul" infrastructure out of the office, which previously has been a luxury that only large organizations could afford. It also allows dynamically scalable resources as virtual services. [2] Considering the case of Mobile Cloud Computing, there are many benefits offered. Mobile devices are very used because of their size and portability. But, smaller size means lower weight, lower hardware performances and smaller battery. These hardware constraints indicate on the development and the capability of the software dedicated for mobile. [3]

Finally, this paper is constructed and diveded in three main sections, where the first section will try to provide a general treat of the Cloud Computing notion, continuing with Mobile Cloud Computing, the meaning, types and challenges, and ending the paper with a table of different cloud providers, their advantages and disadvantages. 


\section{Cloud Computing}

Simply said, Cloud Computing is the delivery of the computing services, such as servers, databases, storage and networking - over the Internet. These services, usually are offered by so called Cloud Providers, that usually charge based on usage.

Nowadays, everyone that is using a device connected to Internet, might be user of cloud services, even though we might not be aware of it. Almost every online service, including email, document editors or entertaining apps, might be running using cloud services.

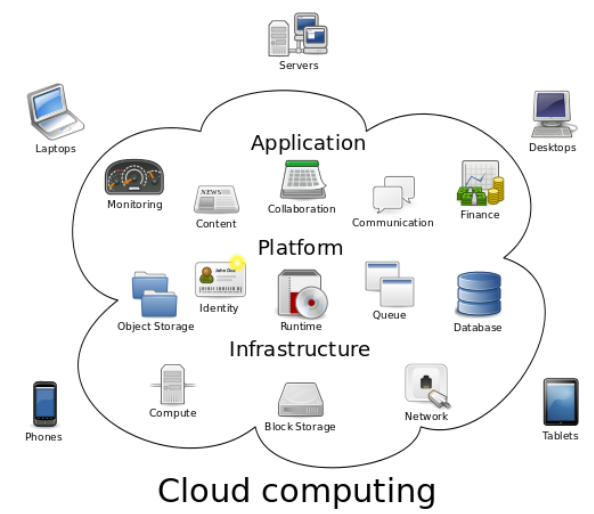

Figure 1: Cloud Computing scheme example [4]

If ever wondered what Cloud Computing is capable of, following is a generally narrow list of the capabilities that Cloud Computing can offer:

- Create new apps and services

- $\quad$ Store, back up and recover data

- Deliver software

- Analyze data for pattern recognition

- Streaming.

Besides the capabilities that Cloud Computing provides, there are also a lot of benefits that it can offer.

- Cost - using cloud services lowers the costs that organizations need to spend for buying hardware and software tools for setting up the infrastructure for its needs.

- Speed - when the organization needs more resources, provisioning additional resources in cloud services can be done is minutes.

- $\quad$ Scaling - the ability to scale elastically on demand using cloud services appears as their main and most common use case - processing power, storage, bandwidth and whatever the demand is, in less than a minute. [5]

Depending on the type of service providers provide, there are several categories of Cloud Computing models, as listed:

\section{Software as a Service}

The providers that provide this model of Cloud Computing solutions, usually provide a webbased application where the users of the service can operate. In this model, the consumer does not have any control over the infrastructure that the service is running in, including the network, servers, storage or operating system. It removes the need that several organizations or companies to install and run their applications or services on their data centers or company computers. By this, the organizations save a lot of financial resources by saving money on the 
hardware they would need to run the application, the rent of space where the data center would be located on, or even software license for operating systems and depending software. [6]

\section{Platform as a Service}

Platform as a Service is another Cloud Computing model in which the third-party provider provides the necessary hardware and software tools - usually required for development or research - over the Internet. In other words, all the programming languages, libraries, services and other programming tools provided by the provider are deployed in the cloud infrastructure that the provider provides. Similar as in the previous model, SaaS, the end user does not have any control or manage any part of the infrastructure, such as network, operating systems, storage, etc. [7]

\section{Infrastructure as a Service}

According to most of information provided by different surveys, IaaS is the most common cloud-based model provided by the service providers. IaaS refers to the service providers who provide processing capability, storage, network and other fundamental computing resources, to the consumer who wants to run any type of software in it. Usually these services are made possible by using virtual machines as instances. Xen, Oracle VirtualBox, KVM or Hyper-V are typical examples of providers that offer great possibilities to run these VMs. [4]

\section{Mobile Cloud Computing}

In the consumer space, mobility players such as Apple, Google, and Microsoft all offer variants of cloud-based apps and private storage. However, the line between the individual and the professional is increasingly being blurred. Allowing employees access to company resources using private devices makes them expect access to your CRM system on their iPad, with (near) real-time business intelligence reports delivered by the touch of a finger while sharing analysis with their teams on the collaboration platform.

Most of the companies tent to move their apps and services in the cloud. Every company mission is to grow and evolve. Considering this case, organizations face trouble with new coming employees, which bring their own devices, services and apps. This means that, it requires more efforts and time to integrate the data to the corporate cloud, in order to ensure support and control over usage of the same. When we add the complex format of making sure that corporate services are up to date, all this process becomes a mess and quite often it becomes a challenging task for the responsible employees. [1]

\section{Advantages}

MCC offers a bunch of advantages while using cloud services. Following are listed some of the most important ones:

- Flexibility - one of key advantages while using MCC is that the cloud information can be used anywhere, everywhere; all you need is a mobile device of any kind, which is paired or configured with the organization cloud platform.

- Real time available data - accessing the data in real time is no longer a challenge while you are out of the office. 
- $\quad$ No upfront payments - last, but not least - payments. Commonly, cloud applications does not require payment without using it. It is mostly the case pay-for-use, which helps in growing the adoption of the model. [8]

\section{Disadvantages}

When there are advantages, it is sure that there are disadvantages as well. Following are listed some of the most important disadvantages of MCC, that every MCC user most keep in mind before using it:

Security - a major concern with Cloud Computing is the security and data integration. When mobile is the subject, the attention must be two times higher: unprotected information can be easily sniffed.

Internet connection - considering the flexibility of MCC, allowing the users to access the data from anywhere, requires Internet connection. Making sure that, when accessing data, the user needs a strong and stable Internet connection, often can cause headache, especially in nonmetropolitan areas.

Performance - considering smaller size and lower hardware performance, it is understandable that the performance with MCC will be in a much lower level. [8]

\section{Mobile Cloud Computing Security Concerns}

One of the most significant concerns of Cloud Computing in general, and Mobile Cloud Computing particularly, without any doubt, is data security.

According to the most recent studies, mobile devices are at the top of the list of the most significant security risks. Confidentiality, integrity and authenticity of information are the most particular threat. Confidentiality is considered in risk when unauthorized parties, somehow, manage to intercept data transmission. Allowing such a thing, risks the integrity of the data. The authenticity is risked when these unauthorized parties can use the devices to trigger transactions. [9]

The latest trends of using mobile devices is by using free applications, which can be infected by malicious software. Using open channels over network threatens confidential information. Thus, these applications are often updated or upgraded, trying to provide as much security as possible.

Following are listed the top threads that occur while using Cloud Computing.

\section{Data Loss}

Using Cloud Computing is more like outsourcing the data to the service provider.

This means increasing the risk of exposing important data, because of the new issues cloud is facing, and which were not issues in traditional computing. Since more of the service providers provide shared resources, it is more likely for the instance to crash and the data to be lost. Recently, there has been a lot of unintentional deletion of data by the providers. Also, a bad line code can mess up access keys, and the data is lost.

To prevent data loss, following solutions can lower the risk:

Encrypt data while transmission;

Using access control tools

Time-to-time back up 


\section{Untrusted service providers}

Also known as malicious insiders, they are the people who have access and are authorized to manage with the data in the service providers offering cloud services. These people can either be working for other companies or they do it for their personal intentions. Not necessarily the company is guilty, in such a case.

\section{Insecure API}

Usually, the communication between a client, which in this case can be a mobile device handled by the company employee, and the server, which in this case is an instance somewhere in the cloud, is done by an Application Programming Interface. In order to keep data integration and security in a higher level, the company providing the API should secure the communication channels and the information transmitted. Avoiding insecure APIs can be achieved by using the following techniques:

- $\quad$ Applying authentication tools and access control tools on data transmission;

Applying authentication tools and access control tools on data transmission;
Implementing the proper security model according to service provider's security protocols. [10]

\section{Conclusion}

Nowadays, Cloud Computing is moving is big steps towards becoming the most popular and the most used technology, either in the organizational context, or smaller units. Considering this, and also considering that mobile technology is another useful technology that provides flexibility, compactness and portability, the big players in the IT industry are really focused in generating as optimal as possible solutions that will fit for mobile devices also.

The research done in this paper is trying to illustrate the latest trends in the IT industry, by providing information from different resources.

Considering the tables, assumptions and everything mentioned in this paper, seems that Mobile Cloud Computing will soon take the lead as the most trendy technology to pay attention to.

\section{References}

1. Lofstad, S.: Trends in Cloud Computing: The Impact of Mobile Devices. Director of Data Center Technologies at Oracle Insight. 2013.

http://www.oracle.com/us/corporate/profit/archives/opinion/011813-slofstad-1899122.html 2. Bahtovski, A., Gusev, M.: Cloud Computing in Mobile Technologies. The $9^{\text {th }}$ Conference for Informatics and Information Technology (CIIT 2012).

3. Shanklin, M.: Mobile Cloud Computing (A survey paper written under the guidance of Prof.

Raj Jain). https://www.cse.wustl.edu/ jain/cse574-10/ftp/cloud/

4. Wikipedia: Cloud Computing. https://en.wikipedia.org/wiki/Cloud_computing

5. Microsoft Azure: What is cloud computing? A beginner's guide.

https://azure.microsoft.com/en-in/overview/what-is-cloud-computing/

6. Rouse, M.: Definition: Software as a Service (SaaS). May, 2016.

http://searchcloudcomputing.techtarget.com/definition/Software-as-a-Service

7. Rouse. M: Definitaion: Platform as a Service (PaaS). September, 2017.

http://searchcloudcomputing.techtarget.com/definition/Platform-as-a-Service-PaaS

8. Mobile Cloud Computing - Pros and Cons. December, 2014.

https://www.getcloudservices.com/blog/mobile-cloud-computing-pros-and-cons/ 
9. Kleiner, C., Disterer, G.: Ensuring mobile device security and compliance at the workplace. Conference on Enterprice Information Systems, HCist 2015, October 7-9, 2015.

10. Aldossary, S., Allen, W: Data Security, Privacy, Availability and Integrity in Cloud Computing: Issues and Current Solutions.International Journal of Advanced Computer Science and Applications, Vol. 7, No. 4, 2016. 